\title{
Wind Energy Potential Assessment in Republic of Macedonia
}

\author{
V.Dimcev, K.Najdenkoski, V.Stoilkov, Z. Kokolanski \\ Faculty of Electrical Engineering and Information Technologies \\ Karpos II, bb, Skopje (Republic of Macedonia) \\ Phone/Fax number:+00389 3099 110, e-mail: vladim@feit.ukim.edu.mk
}

\begin{abstract}
The paper explains latest developments considering exploration of Macedonian wind resources. Problems of choice of location, measurement of wind energy potential, choice of type and unit size of wind turbine generators for the sites, are considered.
\end{abstract}

\section{Key words}

Wind energy, WindPRO software, data analysis, assessment of energy production.

\section{Introduction}

A Wind Atlas of Macedonia was created in 2005. The maps formed the basis for a GIS-based selection of 15 prospective sites where measurements should be done. From those 15 sites, after on sites visits four most promising sites were chosen for further measurement campaign.

After the site screening was completed and careful consideration of all obtained data by the Wind Atlas were made, four sites were chosen for putting into efect the measurement campaign.

Site 1 - Kozuf Mountain is on the south part of Macedonia and has greatest potential for development of wind farm. It is large open grassland on the top of the ridgeline consisting of gently rolling hills. The site elevation between $1300 \mathrm{~m}$ to $1760 \mathrm{~m}$ may produce problems during installation phase and maybe for maintenances of turbines.

Site 2 - Ranovec Hill, Bogdanci, is also on the south part of the country, close to Kozuf mountain. The ridge has 450-500 m elevation and an east-west orientation in an area where the wind prevailing direction is from the northwest-southeast. The vegetation on the site is grass and low shrubs and the site is located between three 110 $\mathrm{kV}$ lines linked into triangle.

Site 3 - Sasavarlija, Stip is located around 20 kilometers to the southeast from the town of Stip on highland with several dispersed hills with low vegetation and a maximum elevation of $996 \mathrm{~m}$.
Site 4 - Bogoslovec, Sveti Nikole, this site is also in the eastern part of the country close to the town of Stip. The site is on short grassland ridge with elevation of up to $750 \mathrm{~m}$.

For the realization of the measurement campaign four complete measurement stations have been provided and installed on the mentioned sites in May/June, 2006. The height of the towers is $50 \mathrm{~m}$.

The measurements system is consisting of four anemometers, two wind direction vanes and thermometer. The wind speed sensors are calibrated according to the MEASNET standard with accuracy class of $0,1 \mathrm{~m} / \mathrm{s}$, which is used by the wind industry in Europe. The wind direction is measured in two different heights for redundancy. Temperature is measured at $2 \mathrm{~m}$, which is a meteorological standard. In addition to sensors there are data loggers inside weather proof cabinets with communication capabilities over GSM line.

\section{Wind data analysis}

For wind data analysis and estimation of energy production, we used software WindPRO and WASP.

In the paper the wind data analysis was conducted for measured data for 24 months, July 2006 to June 2008. Analysis was performed for location Bogoslovec on the eastern part of Macedonia. The average wind speeds for observed period is given in Table 1. For the period of 24 months, average wind speed is $6.53 \mathrm{~m} / \mathrm{s}$.

The wind rose for the same site for observed period is given (Fig. 1). The dominant wind directions are northnorthwest and direction between south-southeast and east-southeast.

The processed measurement data covers $95 \%$ of the measured period. The numerical values refer to the number of registered average values of 10 minute interval throughout a period of 24 hours.

On the basis of conducted analysis of hourly and monthly distribution of wind speed and direction (Figure 2 and 3) it is noticeable that a relatively constant wind speed is maintained almost during the entire period and the 
TABLE I. - Average wind speed

\begin{tabular}{|l|r|r|r|}
\hline & \multicolumn{3}{|c|}{ NRG - 1 50m } \\
\hline & 2006 & 2007 & 2008 \\
\hline January & & 6.82 & 6.75 \\
\hline February & & 8.62 & 7.59 \\
\hline March & & 7.95 & 6.65 \\
\hline April & & 6.96 & 6.59 \\
\hline May & & 6.98 & 6.53 \\
\hline June & 6.31 & 6.85 & 5.31 \\
\hline July & 6.23 & 6.57 & \\
\hline August & 7.82 & 7.72 & \\
\hline September & 6.27 & 5.45 & \\
\hline October & 5.56 & 6.68 & \\
\hline November & 5.18 & 6.4 & \\
\hline December & 6.23 & 6.80 & 6.57 \\
\hline Average & & \multicolumn{2}{|}{} \\
\hline $\begin{array}{l}\text { All Data } \\
\text { Average }\end{array}$ & 6.53 & & \\
\cline { 1 - 3 } & & &
\end{tabular}

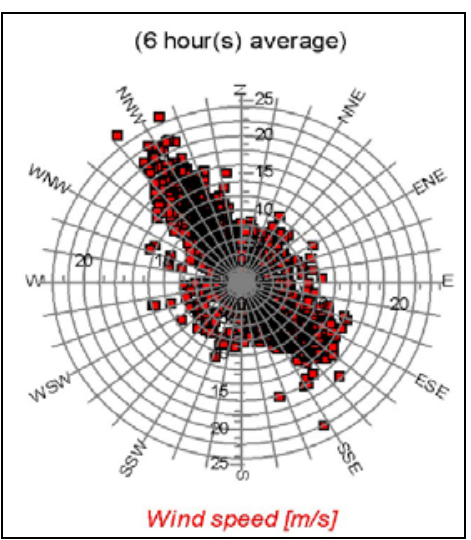

Figure 1. Wind rose for measurment results

prevailing directions are mainly North - Northwest and Southeast.

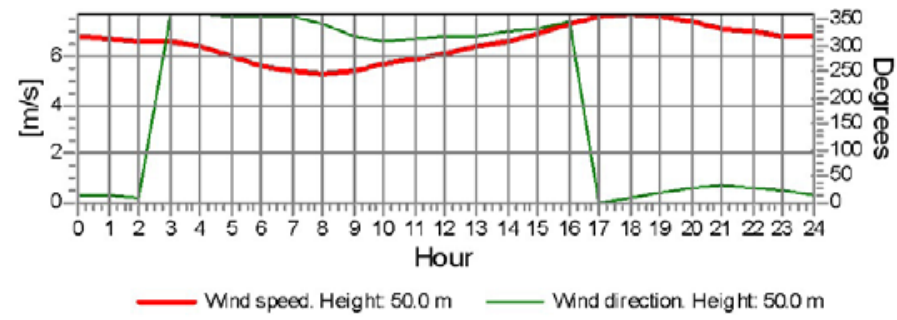

Figure 2. Hourly distribution of wind speed and direction

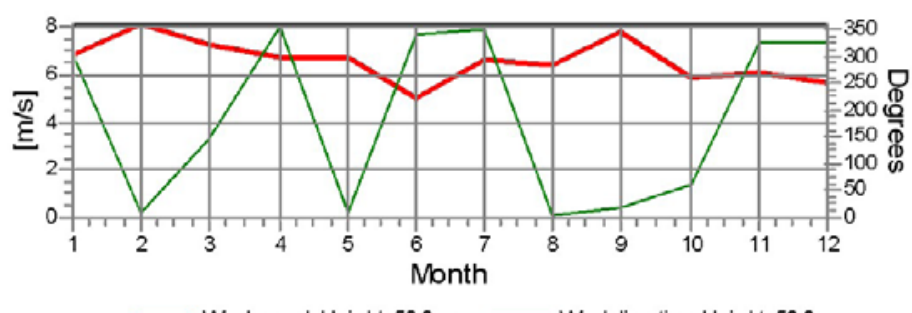

Wind speed. Height $50.0 \mathrm{~m} \quad$ Wnd direction. Height: $50.0 \mathrm{~m}$

Figure 3. Monthly distribution of wind speed and direction
Based on the software analysis performed and the measurements of the wind a wind shear exponent 0.13 has been obtained. This low coefficient is due to the flat surface in the surrounding of the location with very low grassy vegetation. Few characteristic types of terrains for wind shear exponent (Table II).

TABLE II. - Wind shear exponent

\begin{tabular}{|l|c|}
\hline \multicolumn{1}{|c|}{ Terrain } & $\begin{array}{c}\text { Wind Shear } \\
\text { Exponent }\end{array}$ \\
\hline Open water & 0.1 \\
\hline Smooth level & 0.15 \\
\hline Row crops and bushes & 0.2 \\
\hline $\begin{array}{l}\text { Heavy trees, mountainous } \\
\text { terrain }\end{array}$ & 0.25 \\
\hline
\end{tabular}

A linear correlation of measurement data of three heights of measurements at $10 \mathrm{~m}, 30 \mathrm{~m}$, and $50 \mathrm{~m}$ has been obtained.

Figure 4 shows the wind profile i.e. the dependence of the wind speed from the height, for the height of $100 \mathrm{~m}$ above the ground wind speed is around $7 \mathrm{~m} / \mathrm{s}$.

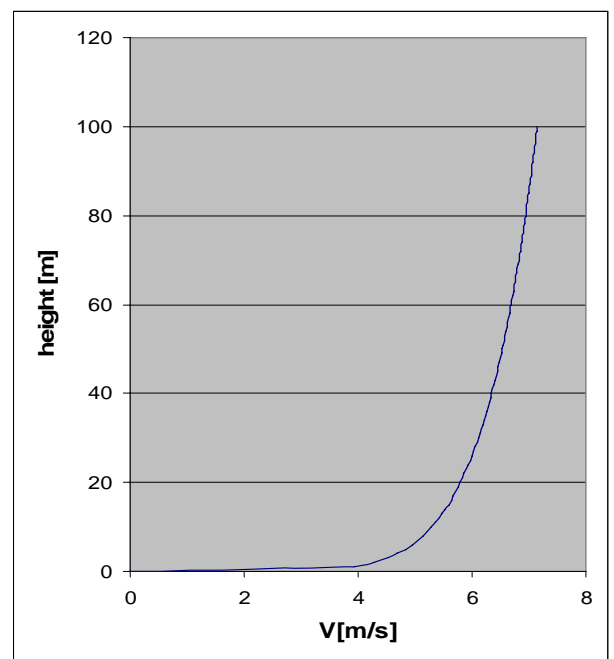

Figure 4. Wind profile

The frequency of the wind speed according to Weibull distribution is shown in Fig. 5. It is noticeable that the speeds $4 \mathrm{~m} / \mathrm{s}$ and $5 \mathrm{~m} / \mathrm{s}$ have the highest frequency with occurrence of $10 \%$. The chart on Fig. 6 confirms that the wind speed is highest reaching average speed of $9 \mathrm{~m} / \mathrm{s}$ from North - Northwest direction.

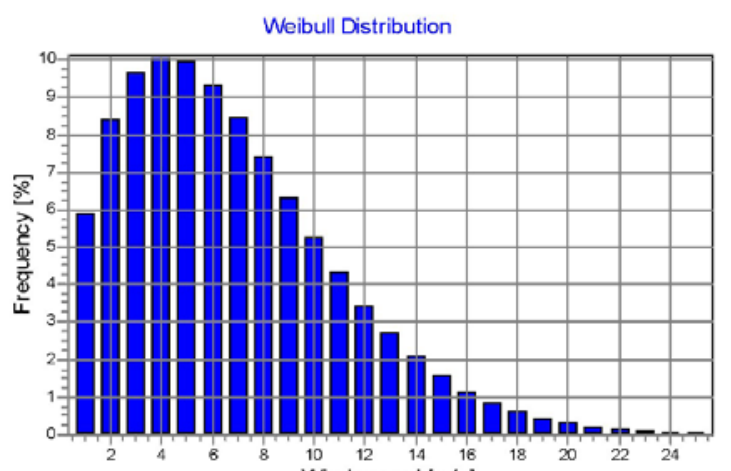

Figure 5. Frequency of the wind speed 


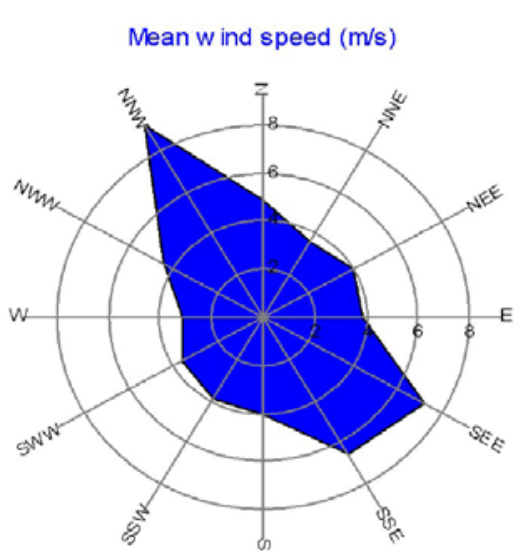

Figure 6. Wind speed vs direction

Fig. 7.a. shows the intensity of the turbulence as a function of the wind speed and Fig. 7.b. shows turbulence vs wind direction. It may be seen that the four main directions of wind blowing are characterized with lower average turbulence of about $6 \%$. If the dependence of turbulence intensity on wind speed is analyzed, it will be noticed that within the range of speed below $30 \mathrm{~m} / \mathrm{s}$, it remains below the $\mathrm{A}, \mathrm{B}$ and $\mathrm{C}$ class levels defined by International Energy Agency (IEA). The main range being of interest for this location is within speed range from 6 to $14 \mathrm{~m} / \mathrm{s}$, in which the turbulence intensity falls bellow the level of average turbulence.

\section{Assessment of energy production}

\subsection{WTG type and unit size choice}

A simulation for annual generation of electricity on the place of measurement location has been performed, where a comparison of the generation of electricity with use of various turbines manufactured by few world reputed manufacturers (Table II) with nacelle heights of $60 \mathrm{~m}$ to $80 \mathrm{~m}$ has been done.

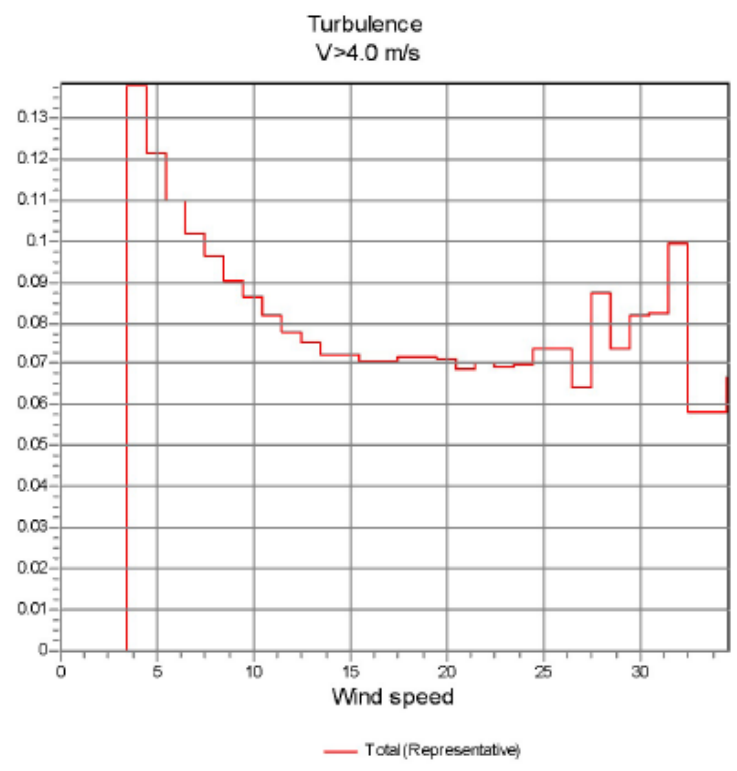

Figure 7.a. Turbulence vs wind speed

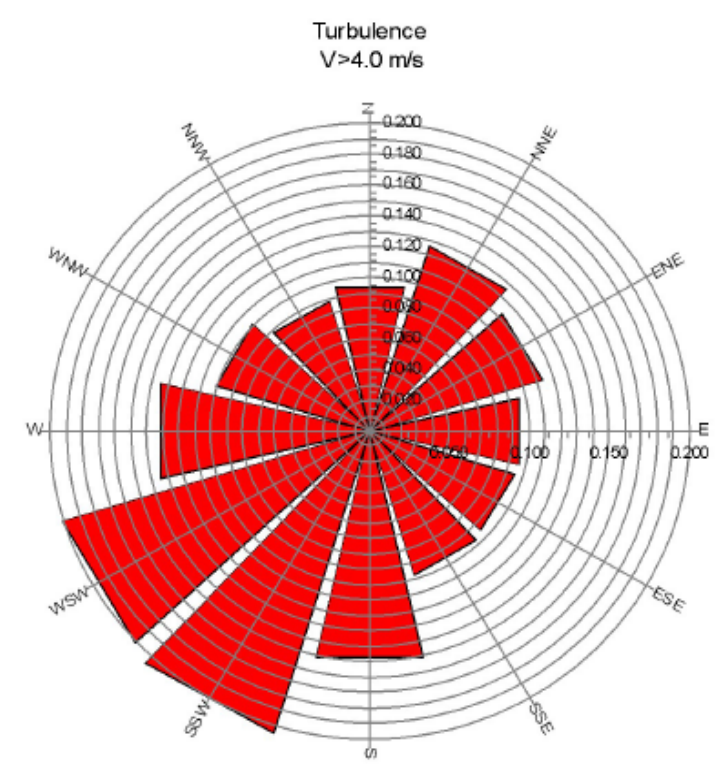

Figure 7.b. Turbulence vs wind direction

TABLE II. - Wind turbine selection

\begin{tabular}{|l|c|c|c|c|}
\hline \multicolumn{1}{|c|}{ Name } & Rated Power [kW] & Rotor Diameter [m] & Height [m] & Anual Energy [MWh] \\
\hline Nordic & 1000 & 54 & 60 & 1.844 \\
\hline Nordex N54/1000 & 1000 & 54 & 60 & 1.776 \\
\hline Vestas V63 & 1500 & 63 & 60 & 2.654 \\
\hline Torres TWT & 1500 & 70 & 60 & 3.075 \\
\hline Fuhrlander FL & 1500 & 70 & 65 & 3.437 \\
\hline GE Wind & 1500 & 70.5 & 64.7 & 3.209 \\
\hline RE Power MD70 & 1500 & 70 & 65 & 3.141 \\
\hline Suzlon S82 & 1500 & 82 & 79 & 3.792 \\
\hline Vestas V80 & 2000 & 80 & 78 & 4.362 \\
\hline AAER A-2000 & 2000 & 80 & 80 & 4.426 \\
\hline Gamesa G83/2000 & 2000 & 83 & 78 & 4.511 \\
\hline DEwind D8/80 & 2000 & 80 & 80 & 4.422 \\
\hline Nordex N90 & 2500 & 90 & 80 & 5.615 \\
\hline Clipper CW89 & 2500 & 89 & 80 & 5.370 \\
\hline Fuhrlander FL 2500 & 2500 & 90 & 85 & 5.658 \\
\hline GE Wind GE2.5 & 2500 & 88 & 80 & 6.613 \\
\hline
\end{tabular}


The analysis of electricity production has been performed on the basis of measurement data about the wind speed and direction at height of $50 \mathrm{~m}$. Average wind speed of $6.6 \mathrm{~m} / \mathrm{s}$ and wind energy of $4.010 \mathrm{kWh} / \mathrm{m}^{2}$ is obtained. Figure 8 shows the distribution of electrical energy production per sector and wind speed.
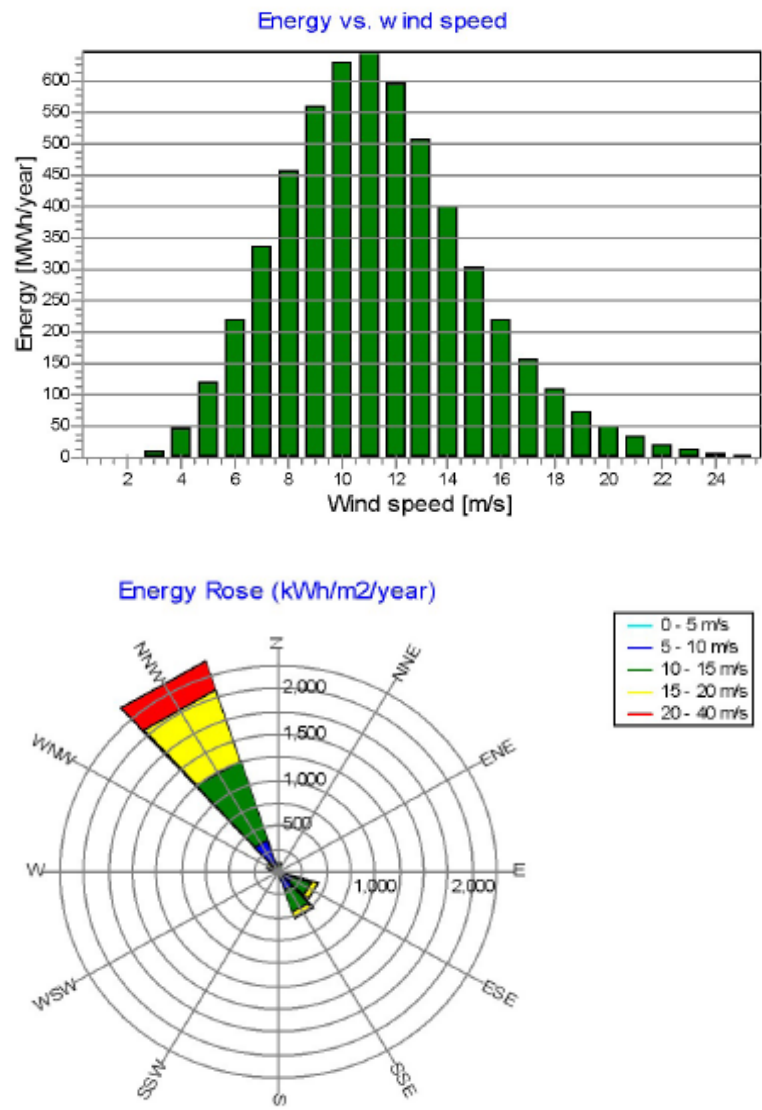

Figure 8 . Electrical energy production per wind speed and sector

The analysis (Fig. 8), shows that the largest amount of electricity is expected from the North-Northwest direction with available electricity of $2250 \mathrm{MWh}$ /year. The largest portion of electricity shall be obtained from wind speeds of $9 \mathrm{~m} / \mathrm{s}$ up to $13 \mathrm{~m} / \mathrm{s}$.

By use of WAsP simulator and statistics of wind speed and direction, a map of wind energy resources in the surrounding of the measurement location is obtained. The result is graphically presented in form of squared outline (Fig. 9) where the simulated value of wind speed is shown with colors within the range from $4.4 \mathrm{~m} / \mathrm{s}$ to $9 \mathrm{~m} / \mathrm{s}$.

\subsection{Wind energy production}

The construction of potential wind power plant is based on acquired map of resources of wind energy (Fig.10) in the surrounding of measurement location, taking into consideration the wind statistics and measured prevailing wind directions.

The wind power plant contains 6 turbines placed at distance of minimum 4 diameters of turbine rotor. To analyze the potential electricity from so conceived windpark, turbines of type VESTAS V63 1500kW have been used. The power curve and the power coefficient for VESTAS V63 is given on Fig.10 and Fig. 11, respectively.

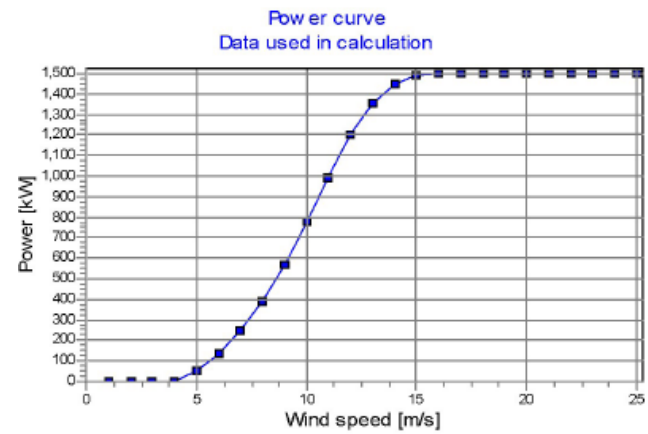

Fig. 10. Power curve of VESTAS V63

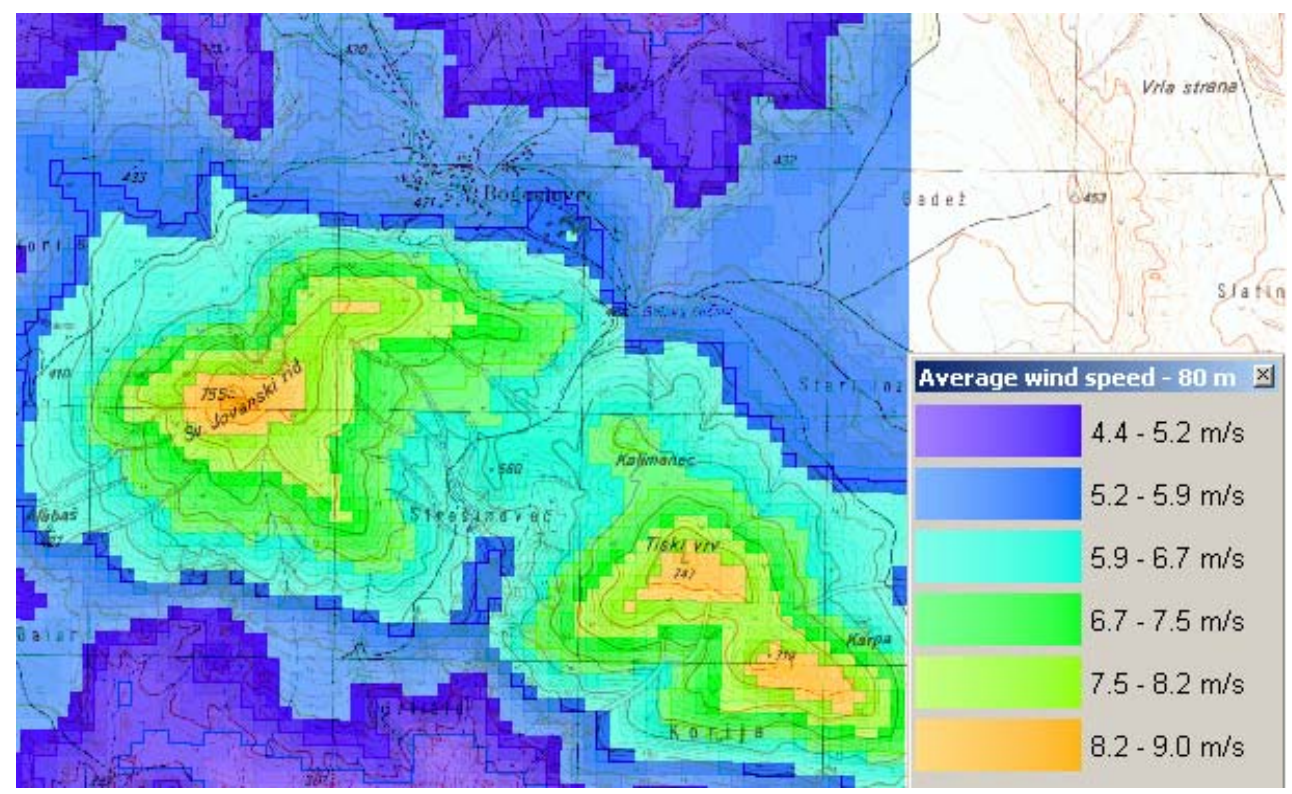

Figure 9. Map of wind resources in the surrounding of the measurement location 


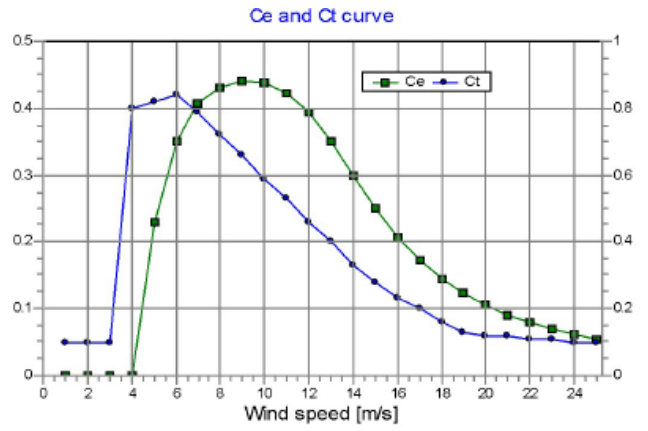

Figure 11. Power coefficients of VESTAS V63

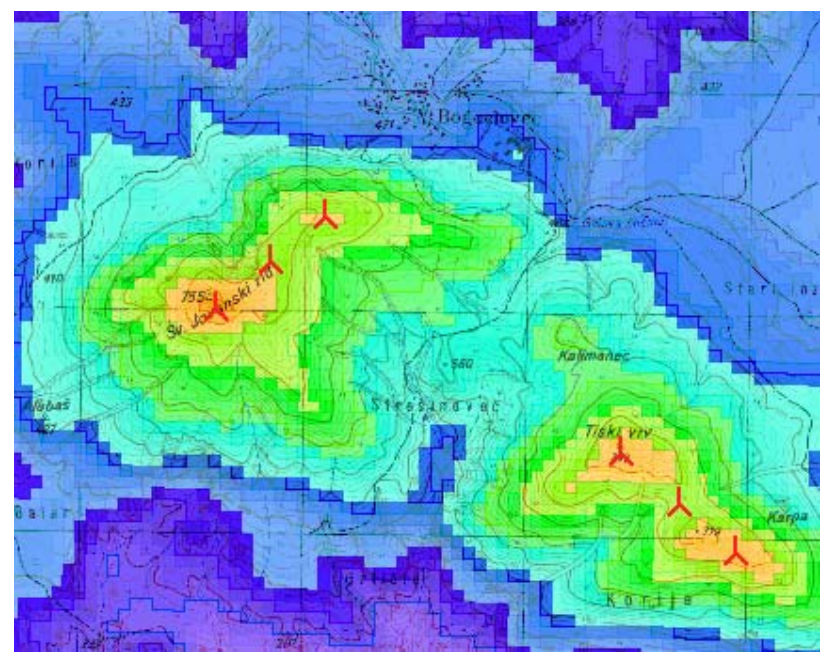

Figure 12. Layout of wind turbine in the wind park

The distribution of the turbines on the terrain is shown in Fig. 12. It may be seen that all turbines according to the simulation have similar potential for generation of electricity and they are characterized with efficiency of about $97 \%$. The average electricity yield per turbine is about $2.865 \mathrm{MWh}$.

TABLE III. - Wind park annual energy production

\begin{tabular}{|c|c|c|}
\hline \multicolumn{3}{|c|}{ Calculated Annual Energy of Wind Farm } \\
\hline \multirow{4}{*}{ Annual Energy } & Result (MWh) & $17,191.2$ \\
\hline & Result $-10 \%(\mathrm{MWh})$ & $15,472.1$ \\
\hline & Efficency (\%) & 97.7 \\
\hline & $\begin{array}{l}\text { Mean WTG energy } \\
(\mathrm{MWh})\end{array}$ & $2,865.2$ \\
\hline \multirow{2}{*}{ Capacity factor for } & Result (\%) & 21.8 \\
\hline & Result $-10 \%(\%)$ & 19.6 \\
\hline
\end{tabular}

The total annual electricity production, by so conceived wind park is about $17200 \mathrm{MWh}$ with underestimate factor of $10 \%$. The average turbine efficiency is $97.7 \%$, the average is $2865.2 \mathrm{MWh}$ per turbine and capacitive factor of $21.8 \%$ (Table III). The electrical energy production per sector, and the losses resulting from mutual influence of turbines is shown in Fig.13.

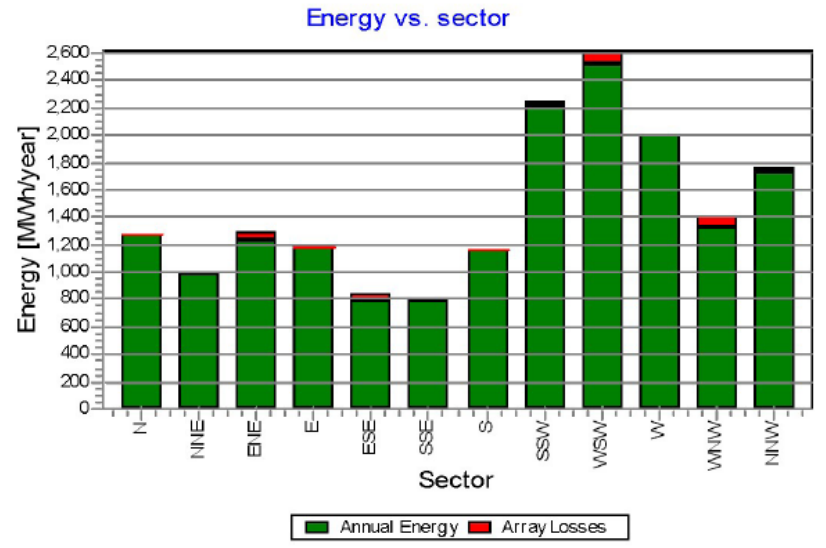

Figure 13. Electrical energy production and losses per sector

The analysis shown on Figure 13, confirms that the largest portion of the electricity is expected from WestSouthwest, South - Southwest and North - Northwest directions. The highest loss of electricity in the wind-park resulting from the park effect comes from WestNorthwest, East-Northeast and East-Southeast.

\section{Conclusion}

Comprehensive action has been started in order to determine the country wind energy potential in 2005 . The wind atlas has been created and on the basis of its results 4 most perspective sites were chosen for measurement campaign. The measurements started in the middle of 2006.

This paper presented wind data analysis from one site on the eastern part of Macedonia. The estimation of energy production has been carried at the same location with 6 wind turbines, with rated power of 1.5 MW each.

\section{Acknowledgement}

This paper is a part of the project financed by the Norwegian Ministry of Foreign Affairs trough the Sector for Euro Integration of the Republic of Macedonia. The active participant from Norwegian side has been NTE Company from Steinkjer. The authors wish to express their appreciation to the above mentioned subjects.

\section{References}

[1] Wind Energy Resource Atlas and Site Screening of the Republic of Macedonia, AWS Truewind, June, 2005.

[2] Monitoring Program of Macedonian Wind Resources, Project Funded by Norwegian Ministry of Foreign Affairs, November, 2005.

[3] V. Dimcev, K. Najdenkoski, V. Stoilkov: Exploration of wind energy potential in Republic of Macedonia, Balkan Power Conference, Ohrid, 2006.

[4] S. Mathew: Wind Energy, Fundamentals, Resource Analysis and Economics, Springer-Verlag, 2006. 